\title{
Causality and aspect in ability, actuality, and implicativity*
}

\author{
Prerna Nadathur \\ University of California, Berkeley
}

\begin{abstract}
Past-tense ability ascriptions (e.g., was able) alternate between conveying pure, potentially unrealized ability and an interpretation which actualizes the ability. The alternation extends to ability modals, with actualized readings strengthening to actuality entailments under perfective aspect in aspect-marking languages (Bhatt 1999). These interpretations resist explanation on accounts which seek to derive them in the composition of modality and aspect. I build on causal analyses of implicative inferences (from lexical implicatives like manage as well as 'variablyimplicative' enough comparatives; Baglini \& Francez 2016; Nadathur 2016, 2017) to propose a new approach to actuality inferences, grounded in a causal semantics for ability predicates. This account derives both pure ability and actuality readings, and explains parallels between implicative manage and actualized ability on the basis of shared (presuppositional) causal structure. Manage and ability differ in asserted content, but the difference is neutralized-producing actuality entailments—under a perfective operator which selects for eventive predicates, and combines with stative ability attributions only via aspectual coercion (de Swart 1998, a.o.).
\end{abstract}

Keywords: ability, actuality entailments, aspectual coercion, causal dependence, enough constructions, eventives, grammatical aspect, implicatives, manage, statives

\section{Introduction}

Across languages, past-tense attributions of ability exhibit a curious duality in their interpretation. As Thalberg (1972: 121) observes, English was able "sometimes means 'had the ability', and sometimes means 'did'."

(1) a. In her twenties, Marja was able to swim across Lake Harriet. $\sim$ In her twenties, Marja had the ability to swim across Lake Harriet.

b. Yesterday morning, Marja was able to swim across Lake Harriet. $\sim$ Marja swam across Lake Harriet yesterday morning.

(1a) is naturally understood to ascribe a certain level of skill in swimming to Marja during her twenties, and on this reading does not require that she has ever

* Thanks are due to Cleo Condoravdi, Itamar Francez, Beth Levin, and Dan Lassiter for discussion of these ideas, and to Eva Portelance and Jérémie Wenger for their insights into the French data. 
crossed the lake. ${ }^{1}$ (1b), however, privileges a reading on which Marja actually crossed Lake Harriet yesterday morning. Notably, this reading requires only a single crossing, and fails to license general conclusions about Marja's swimming skills.

The alternation extends to abilitative uses of possibility modals, and is disambiguated by aspect in languages which mark this grammatical distinction overtly (Bhatt 1999). Thus, while an imperfective use of French pouvoir ('can') is compatible with pure ability, its perfective counterpart entails complement actualization:

a. Marja pouvait traverser le lac à la nage, mais elle ne l'a pas traversé. 'Marja could-IMPF swim across the lake, but she did not cross it.'

b. Marja a pu traverser le lac à la nage, \#mais elle ne l'a pas traversé. ${ }^{2}$ 'Marja could-PFV swim across the lake, \#but she did not cross it.'

Actuality entailments, as in (2b), are striking and (prima facie) unexpected: possibility modals usually introduce hypotheticality, and there is no obvious reason that the perfective aspect should erase this contribution. It is thus not surprising that most of the literature on actuality focuses on the composition of aspect and modality in examples like (2b). This focus, however, sidelines an important clue to the puzzle, by setting aside the observation that it is not just actuality entailments which call for explication, but the existence of actualized interpretations-and indeed, ability/actuality alternations - across the board. In other words, the puzzle of actuality is as much about the meaning of ability as it is about modality and aspect.

I propose a new treatment of actuality inferences, grounded in the semantics of ability. The approach is inspired by Bhatt (1999), who compares actuality entailments to the characteristic complement entailments of the implicative verb manage (Karttunen 1971). Based on recent causal treatments of implicativity (Baglini \& Francez 2016; Nadathur 2016), I argue that ability and manage do indeed share semantic structure, backgrounding the causal dependence of their complements on some prior action or event. On this proposal, ability and manage differ only in assertion. Manage asserts the occurrence of its causal prerequisite, but ability ascriptions, in keeping with their modal flavour, at base establish only the prerequisite's potential occurrence. Drawing on evidence from 'variably-implicative' enough comparatives (be fast enough; Hacquard 2005; Nadathur 2017), I argue that this latent potential composes with perfective aspect as a stative predicate, triggering an operation of aspectual coercion (de Swart 1998, a.o.) which activates the underlying implicative structure by forcing instantiation of the causal prerequisite. Since actuality inferences result from the interaction between a complex causal structure for ability

1 While some evidence of swimming skill may be needed to license (1a), it can be supplied by something other than a crossing of Lake Harriet-e.g., by regular crossings of a larger lake.

2 Following Hacquard 2006, the French passé composé is marked as perfective throughout the paper. 
Causality and aspect in ability, actuality, and implicativity

and the selectional restrictions of perfective aspect, the account predicts actualizing inferences in other contexts where the same semantic components are in play.

\section{The problem of pure ability}

\subsection{Modality, aspect, and ability}

One reason to investigate the role of ability is that actualized interpretations arise not only from ability modals, but also from 'semi-modal' predicates like be able. ${ }^{3}$ Perfective possibility modals, on the other hand, do not always actualize: Hacquard (2020: 3 ) provides the following example of non-actualizing epistemic possibility.

Jean a (bien) pu partir, mais il est aussi possible qu'il soit resté. 'Jean may-PFV (well) have left, but it is also possible that he stayed.'

Even if, as argued by Hacquard and others, ability is not the only actualizing modality, the non-universality of actualization suggests that some specific set of semantic features are implicated in the phenomenon. ${ }^{4}$ At the very least, then, an investigation of ability promises to shed light on these 'actualizing' features.

Moreover, (naïve) composition of modality and aspect does not predict actuality. Based on the relatively standard assumptions in (4) (Klein 1994; Kratzer 1998), we expect an interpretation like (5) for (2b), instantiating a reference-time lake crossing in some world accessible from, but not necessarily identical to, the evaluation world-i.e., a reading where the possibility of the prejacent is fully contained within the reference time supplied by tense.

a. \PST is defined if $t \prec t^{*}$. If defined, $\llbracket \mathrm{PST} \rrbracket=t$

b. $\llbracket \mathrm{PFV} \rrbracket:=\lambda w \lambda t \lambda P . \exists e[\tau(e) \subseteq t \wedge P(e)(w)]$

c. $\llbracket \operatorname{CAN}(\phi) \rrbracket^{\mathrm{ACC}}:=\lambda w \lambda t \lambda e \cdot \exists w^{\prime} \in \operatorname{ACC}(w)\left[\phi(e)\left(w^{\prime}\right)\right]$

$\llbracket(2 \mathrm{~b}) \rrbracket^{w^{*}, t^{*}} \equiv \llbracket \operatorname{PST}\left(\operatorname{PFV}\left(\mathrm{CAN}_{\mathrm{circ}}(\right.\right.$ Marja swim across the lake $\left.\left.)\right)\right) \rrbracket^{w^{*}, t^{*}}$

$=\exists e\left[\tau(e) \subseteq t\left\{t \prec t^{*}\right\} \wedge \exists w \in \operatorname{CIRC}\left(w^{*}\right)[\operatorname{swim}-\operatorname{across}-\operatorname{lake}(e)(w) \wedge \operatorname{AG}(M)(e)]\right]$

On her prominent account of actuality entailments, Hacquard (2006) proposes to modify aspect's contribution so that it instantiates an evaluation world eventuality that is a counterpart of the modal eventuality. The counterparts are then, by assumption, constrained to share a description, so that the actual event is itself a realization of the prejacent. ${ }^{5}$ For Hacquard, actualizing and non-actualizing modalities are

3 See also Castroviejo \& Oltra-Massuet 2018 on Spanish ser capaz ('be capable').

4 The precise characterization of actualizing modalities is disputed: Hacquard claims that all 'root' modalities actualize, while Mari (2016) restricts actualization to teleological modals.

5 The principle Hacquard (2006: 57) adopts to preserve event descriptions across worlds introduces additional complications; see Nadathur 2019 (54-55) for further discussion. 
distinguished by the relative scope of aspect and modality (with non-entailing modalities above aspect), and the absence of actuality in, e.g., (2a) is attributed to a generic operator introduced by the imperfective (cf. Bhatt 1999). One problem with this analysis is that it predicts that the complement entailments of the French implicative réussir ('manage', 'succeed'), which also scopes below aspect, should also be abrogated by the imperfective. Example (6) shows that this is not the case. ${ }^{6}$
a. Jean réussissait à s'enfuir, \#mais il ne s'est jamais enfui.
'Jean managed-IMPF to escape, \#but he never escaped.'
b. Jean a réussi à s'enfuir, \#mais il ne s'est pas enfui.
'Jean managed-PFV to escape, \#but he did not escape.'

The contrast between (6a) and non-entailing (2a) is particularly significant in light of the parallel between manage/réussir and actualized ability, discussed in $\S 3$.

\subsection{The meaning of ability}

Approaches like Hacquard's overlook another reason to suspect that ability-not just possibility—contributes to the ability/actuality alternation: even on pure ability readings, ability ascriptions do not behave like circumstantial possibilities. The inference schemes in (7) highlight important points of divergence. Both patterns are valid when $\diamond$ is circumstantial possibility, but fail for abilitative can (Kenny 1976). ${ }^{7}$
a. $p \rightarrow \diamond p$
b. $\diamond(p \vee q) \rightarrow \diamond p \vee \diamond q$

Example (8) illustrates the problem with (7a). (8a) is not licensed in the given context. The problem is about reliability: while it is evidently circumstantially possible that Tara makes a hole in one, her history precludes an ability to do so. Abilitative can, it seems, has stronger truth conditions than circumstantial possibility.

(8) Context: Tara is a beginning golfer. She misses most of her shots. On this occasion, however, she strikes the ball from the tee and it happens to go into the hole, so on this occasion she makes a hole in one.

(Maier 2018)

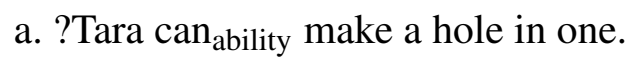

Since pure ability claims like (1a) and (2a) are acceptable in contexts where their prejacents have never occurred, a reliability requirement cannot be reduced to one of (past) regularity. The nature of the requirement becomes clearer when we consider why abilitative can does not license (7b). (9) is based on an example from Kenny:

6 Other objections are discussed in Mari \& Martin 2009; Piñón 2009; Portner 2009; Homer 2011.

7 (7a) follows from the assumption that circumstantial modal bases are realistic. For (7b), if there is a circumstantially accessible world in which either $p$ or $q$ holds, it follows that there is either a circumstantially accessible world in which $p$ holds or one in which $q$ holds. 
(9) Context: We have a randomly shuffled deck of cards, equally distributed between red and black. Karl is about to pick a card from the face-down deck.

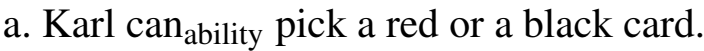

b. \#Karl can ability $_{\text {pick a red card or Karl can }}$ ability pick a black card

(9a) is clearly true, but (9b) is false. The two claims are differentiated by the availability of a strategy which Karl can use to ensure a specific outcome. In (9a), he simply needs to reach out and take a card, and he will pick a card which is either red or black. There is nothing he can do, however, to ensure that his card is red, or to ensure that it is black. In the absence of a strategy for either colour, (9b) fails.

This suggests that ability predicates are structured as complex hypothetical guarantees (to borrow a term from Mandelkern, Schultheis \& Boylan 2017), where some possible action of the agent ensures (necessitates) the realization of the complement. The connection between ability and possibility comes from the idea that the ensuring strategy is merely available to an agent, while the reliability needed for (8a) and (9b) follows from the embedded necessity of the prejacent (given implementation of the strategy). A two-tiered structure of this sort is not a new idea: in addition to Mandelkern et al.'s 'act conditional' analysis, Brown (1988) introduces a compound (possibility-over-necessity) modal operator for ability, while Belnap (1991) argues that ability modals are represented by historical possibility operators embedding an agentive 'seeing to it that' (stit) proposition (in which an agent brings an event about by means of a prior choice; Belnap \& Perloff 1988). Louie (2014) and Maier (2018) make similar proposals: while the precise implementation of the idea differs from one account to another, they agree on the basic structure in (10).

(10) Proposal. Given an agent $x$ and a one-place predicate $A, x \operatorname{can}_{\text {ability }} A$ is true just in case there is some contextually-available action $H$ for $x$ such that if $x$ does $H$, then $x$ will do $A$.

Proposal (10) requires some additional details. To maintain the intuitive connection between possibility and ability, the notion that $H$ is 'contextually available' must be understood, roughly, as indicating that $H(x)$ is a 'live' possibility: there should be circumstantially accessible worlds in which $x$ acts on $H$ at reference time. The relationship between $H(x)$ and $A(x)$ also needs clarification: if $H(x)$ is an ensuring strategy for $A(x)$, the modal relationship between them should capture that the occurrence of $H(x)$ brings about the occurrence of $A(x)$. I leave the content of a bringing about relation undetermined at present, and return to it at the end of $\S 3$.

\section{Chasing the actuality interpretation}

While it gives us a handle on pure ability, proposal (10) leaves actuality inferences all the more perplexing. The structure of (10) is motivated in part by the failure of 
inference pattern (7a) ( $p \rightarrow \diamond p)$. But, at least at first glance, this pattern seems to be what actualized ability is all about: the licensing of (past-tense) ability ascriptions on the basis of a single actualization of their complements.

If we examine actualized ability more closely, however, it turns out that there is more to this interpretation than complement realization. Bhatt (1999) draws a comparison between the actualized interpretations of ability and the inferential profile of implicative manage (as opposed to the simple 'did' of Thalberg 1972).

(11) Marja managed to swim across Lake Harriet (\#but she did not cross it).

Manage gives rise to two key inferences, both of which are shared by actualized ability. First, as shown in (11), manage entails the realization of its complement. Secondly, it adds to this an impression of non-triviality, which Bhatt (following Karttunen \& Peters 1979) describes as a presupposition that complement realization was effortful. Thus, both managed and was able are acceptable in (12) if it is common knowledge that Timmy has suffered significant loss of muscular control, but become infelicitous if he is known to be in good physical condition.

(12) Timmy managed/was able to breathe normally.

Bhatt proposes that the predicate ABLE (encompassing both ability modals and 'semi-modals' like be able) is itself an implicative, sharing the lexical semantics and therefore the inferential profile of manage. This leads to a familiar problem: a shared semantics predicts identical interpretations for ABLE and manage under aspectual marking, but as we have seen for French réussir in (6a), imperfective implicatives retain their complement entailments, while imperfective ABLE does not (as in 2a).

This difference rules out a fully-implicative semantics for ABLE, but does not preclude an account on which Bhatt's central thesis-that actuality entailments are, semantically, instances of implicativity - is upheld. On this approach, the semantic components responsible for manage's characteristic inferences would also derive actualized ability. Instead of being lexical components of ABLE, however, they would arise in the composition of ABLE and perfective aspect. In the rest of this section, I outline an account of the lexical semantics of manage which offers a clear picture of the semantic components of implicativity, and then consider how this proposal relates to the hypothetical guarantee account of ABLE introduced in $\S 2.2$.

\subsection{Manage and causal dependence}

A semantics for manage must predict the two-way entailment pattern in (13), without predicting equivalence between an implicative assertion and its complement (Karttunen 1971). The false equivalence is usually ruled out on the basis of presuppositions introduced by the matrix verb, as in Karttunen \& Peters 1979. 
Causality and aspect in ability, actuality, and implicativity

(13) a. Ria managed to solve the problem. $\rightarrow$ Ria solved the problem.

b. Ria didn't manage to solve the problem. $\rightarrow$ Ria didn't solve the problem.

One problem with the Karttunen \& Peters analysis — on which manage directly asserts its complement, and presupposes its difficulty-is that the presuppositions of manage appear to vary from case to case (Coleman 1975; Baglini \& Francez 2016). In some contexts, we readily infer that the manage-complement required effort, but in others, effort can be explicitly denied without infelicity. In these cases, we may instead infer that the subject attempted, or at least intended, to bring about the complement, or simply that the complement was unlikely/not expected to occur.

a. By 1998 [...] manufacturers had easily managed to bypass the law [...] ${ }^{8}$ $\Varangle$ effort, $\rightsquigarrow$ intention, ? $\rightsquigarrow$ unlikelihood

b. Without intending to, Ms. Streisand actually managed to synthesize the problem of diversity mania. $\quad \Varangle \rightarrow$ intention, $\not \rightarrow$ effort, $\rightsquigarrow$ unlikelihood

c. The social democrats managed to strengthen their position [...] as expected during local elections. $\quad \rightsquigarrow$ intention, ? $\rightsquigarrow$ effort, $\longleftrightarrow$ unlikelihood

Baglini \& Francez (2016) argue that manage must presuppose something more general than effort, intention, or unlikelihood, in order for context changes to permit the observed variation. Their crucial insight is that manage requires the realization of its complement to be causally dependent on prior events. Thus, while the complement might be easy, expected, or unintended in any given context, the inference that it was not without prerequisite produces a general sense of non-triviality.

Proposal (15) paraphrases an account of implicatives from Nadathur 2016, 2019, which builds on and preserves Baglini \& Francez's key insights. First, manage backgrounds its complement's causal dependence. Secondly, the complement is not directly asserted, but follows instead as a causal consequence of presupposition and assertion. The main revision adds a causal sufficiency presupposition to Baglini \& Francez's causal necessity, which allows the account to be extended to implicatives like dare, which specify something about the nature of a causing action (see 16). ${ }^{9}$

(15) Proposal. Given an agent $x$ and one-place predicate $A, x$ manage (to) $A$ :

a. presupposes the existence of an action $H$ such that $H(x)$ is causally necessary and causally sufficient for $A(x)$ in the utterance context. ${ }^{10}$

b. asserts $H(x)$ (i.e., that $x$ does $H$ )

8 Examples (14a)-(14c) are naturally-occurring. Baglini \& Francez (2016) provide similar examples. 9 (15) is a precisification of Karttunen's (1971: 352) suggestion that the "central part" of an implicative claim is a necessary/sufficient condition for its complement. The causal component is supported by manage's infelicity in contexts which background only non-causal conditions (Nadathur 2019: Ch.3). 10 Equivalently, $H(x)$ is the only unresolved causally necessary condition for $A(x)$. 
(16) a. Morgan dared to enter the cave.

$\rightarrow$ Morgan entered the cave. (because she acted with courage)

b. Morgan did not dare to enter the cave. $\rightarrow$ Morgan did not enter the cave. (because she did not act with courage)

The crucial dependence relations are formalized in terms of Schulz's (2011) structural equation framework for causal entailment. Informal definitions follow:

(17) Causal dependencies. Given events $C$ and $E$, and a context $s$ which does not fix $C$, and does not have $E$ as a causal consequence:

a. $C$ is causally necessary for $E$ in $s$ if:

i. there is a situation compatible with $s+C$ (the update of $s$ with $C$ ) which does not fix $E$, but has $E$ as a causal consequence.

ii. no situation compatible with $s$ which does not fix $E$ has $E$ but not $C$ as a causal consequence.

b. $C$ is causally sufficient for $E$ in $s$ if $E$ is a causal consequence of $s+C$

Roughly, $C$ is causally necessary for $E$ if $C$ is required for $E$ to be possible, and causally sufficient for $E$ if it guarantees $E$ (in the given context).

These definitions can be integrated with a modal premise semantics, along the lines laid out in Kaufmann 2013. In this frame, an event $C$ is causally sufficient for $E$ in context $s$ if $E$ is modally necessary, given $s+C$, and causally necessary for $E$ if $\neg E$ is modally necessary, given $s+\neg C$ (see Nadathur 2019). Manage thus has a tiered modal structure, where a potential action of agent $x$ is determinative for the complement (leading to the impression of non-triviality). Crucially, asserting manage establishes the causing action, leading to complement realization (on the reasonable assumption that the actual world is causally normal). A negated claim denies the occurrence of the causing event, precluding complement realization.

\subsection{Implicativity and actuality inferences}

Proposal (15) establishes the following three semantic components for implicativity:

a. the (backgrounded) existence of a condition (action or event) which is both necessary and sufficient for the complement

b. a causal flavour for the necessity/sufficiency relations

c. an assertion establishing the occurrence of the causing condition

On the thesis that actuality entailments are implicative entailments, these are the ingredients that must emerge in the composition of ABLE and perfective aspect.

There is already a striking similarity between (15) and the hypothetical guarantee structure suggested for ABLE in $§ 2.2$. In both cases, complement realization hinges 
on some available action associated with the matrix verb. Moreover, we have seen that ABLE, like manage, is infelicitous in contexts where its complement is assumed to be trivial. This supports the idea that ABLE shares manage's presuppositions.

Pursuing the implicative hypothesis allows us to further flesh out Proposal (10) for ABLE. Most significantly, we can recast the bringing-about relationship between $H(x)$ and $A(x)$ as one of causal dependence-i.e., as one in which $A(x)$ follows as a normal causal consequence of $H(x)$. The addition of causal necessity is supported by (19), which shows that negating ABLE entails the negation of its complement.

(19) Ria was not able to solve the problem. $\rightarrow$ Ria did not solve the problem.

Modulo these details, the hypothetical guarantee analysis-which was motivated by pure rather than actualized ability — has the first two components of implicativity.

ABLE and manage differ, however, in one key respect. Implicative verbs assert the occurrence of their causal prerequisites, initiating the causal chain. The complement entailment follows as a consequence of this. ABLE does not make the same assertion (and cannot, in the general case). Instead, ABLE establishes only the latent potential, or availability, of the causing action, attributing to agent $x$ the capacity to do $H(x)$, but not requiring that $H(x)$ occurs. If we wish to take the implicative approach to actuality any farther, then, it seems as if the addition of overt perfective marking will need to fundamentally alter the asserted content of ABLE. Specifically, it will need to produce an (implicative) assertion which forces instantiation of the causing action.

In one way, we seem to be back where we started, with the perfective mysteriously realizing something that ought only to be a possibility. Despite this apparent setback, we have made headway on the original problem. For one, in bringing together the reliability requirement of pure ability with the internal structure of an implicative, the hypothetical guarantee account of ABLE offers the potential for a unified treatment of pure ability and actuality, thereby providing an explanation of the crosslinguistic prevalence of the alternation. Secondly, the possibility now in need of instantiation has a very specific character: it arises by way of an agent's potential for taking a particular (type of) action. Viewed in this way, an ability assertion is a type of property attribution: crucially, it represents a stative predicate, albeit one which is inherently associated with action.

This characterization of ability ascriptions is at the heart of their aspect sensitivity. As it turns out, actionable property attributions of this sort have a special status with respect to aspectual composition. To illustrate this point, and its consequences for the derivation of actuality inferences, I next discuss the 'variably implicative' behaviour of complement-taking enough comparatives. 


\section{Enough, variable implicativity, and aspectual coercion}

Enough comparatives like (20) can be analyzed as degree-based property attributions with a modal component: for agent $x$, gradable adjective ADJ, and predicate $A, x$ be ADJ enough to $A$ attributes to $x$ a degree of ADJ that is at least as great as the degree required to realize $A(x)$ (Meier 2003; von Stechow, Krasikova \& Penka 2004, a.o.).

\section{(20) Juno was fast enough to win the race.}

$\rightsquigarrow$ Juno won the race.

These constructions give rise to implicative inferences under certain conditions. Where they occur, the complement inferences show the same sensitivity to aspect as the actuality inferences of ability claims. Enough implicativity in English is at best defeasible, as indicated in (20), while French être assez rapide ('be fast enough') is compatible with complement denial under imperfective marking, but entails its complement in the perfective (first noted in Hacquard 2005).

(21) a. Juno était assez rapide pour gagner la course, mais elle n'a jamais gagné. 'Juno was-IMPF fast enough to win the race, but she never won.'

b. Juno a été assez rapide pour gagner la course, \#mais elle n'a pas gagné. 'Juno was-PFV fast enough to win the race, \#but she did not win.'

Two other factors affect enough implicativity. First, as noted by Meier (2003), the modal relationship between the matrix adjective and the complement must be circumstantial. No inference arises from (22), for instance, where (sufficient) age is understood to be relevant for alcohol consumption only in a deontic (legal) capacity.

(22) Amira was old enough to drink alcohol.

» Amira drank alcohol.

Further variation arises within the circumstantial subgroup, which Nadathur (2017) links to the nature of the adjectival property. Implicativity arises in (20), where the property attributed by the matrix adjective fast is dynamic (or actionable) in nature, attributable to an agent only in view of their potential to perform actions characterized by speed. In (23), on the other hand, the attributed property (height) is essentially static: tall applies directly to an individual, without reference to any actions they might or might not take.

Nima was tall enough to reach the shelf.

$\leftrightarrow \rightarrow$ Nima reached the shelf.

The components of 'true' implicativity come together only in the composition of circumstantial enough with a dynamic adjective and perfective aspect. Understanding how this occurs illuminates the interaction between actionable-property attributions and perfective aspect that sits at the core of actuality entailments. 
Causality and aspect in ability, actuality, and implicativity

\subsection{The semantics of enough constructions}

Available analyses of enough comparatives agree for the most part on a semantics which derives interpretations along the lines paraphrased in (24). ${ }^{11}$ I adopt von Stechow et al.'s (2004) treatment of enough as an equative with a built-in necessity modal. Assuming that gradable adjectives relate individuals to (sets of) degrees (cf. Kennedy 2001), this predicts (27) for the interpretation of (24)'s sentence radical.

(24) Juno is fast enough to win the race.

$\sim$ Juno is as fast as she has to be in order to win the race.

$$
\begin{aligned}
& \llbracket \text { enough } \rrbracket:=\lambda w \lambda A_{\text {set }} \lambda P_{\text {sedt }} \lambda x . \\
& \qquad\{d: P(x)(d)(w)\} \supseteq\left\{d: \forall w^{\prime} \in \operatorname{ACC}(w)\left[A(x)\left(w^{\prime}\right) \rightarrow P(x)(d)\left(w^{\prime}\right)\right]\right\} \\
& \llbracket \text { fast } \rrbracket:=\lambda w \lambda x \lambda d . \operatorname{SPD}(x)(w) \geq d \\
& \text { Juno be fast enough to win the race. } \equiv \\
& \left\{d: \forall w^{\prime} \in \operatorname{CIRC}(w)\left[\text { win-race }(J)\left(w^{\prime}\right) \rightarrow \operatorname{SPD}(J)\left(w^{\prime}\right) \geq d\right]\right\} \subseteq\{d: \operatorname{SPD}(J)(w) \geq d\}
\end{aligned}
$$

This analysis is naturally associated with a presupposition that the enoughcomplement is realized in at least one accessible world. This reduces to the necessity condition in (28), establishing that the agent cannot realize the complement below some minimum degree $d_{\mathrm{n}}$ of the matrix adjective (cf. Hacquard 2005).

$$
\text { Necessity condition. } \exists d_{\mathrm{n}}\left[\forall w^{\prime} \in \operatorname{ACC}(w)\left[\neg \operatorname{ADJ}(x)\left(d_{\mathrm{n}}\right)\left(w^{\prime}\right) \rightarrow \neg A(x)\left(w^{\prime}\right)\right]\right]
$$

Given (28), circumstantial enough establishes the possibility for an agent to realize the complement (in view of the degree attribution), but nothing further. ${ }^{12}$

There is a certain similarity between enough comparatives and the semantics of implicatives, insofar as both construction types relate a condition associated with the matrix predicate to the realization of their complements. Despite this, the basic enough semantics is not truly implicative, in the sense of Proposal (15). For one, the matrix-complement relationship appears to be only one of necessity, rather than the necessity/sufficiency relationship of implicative verbs. Indeed (and contra Hacquard 2005), we do not want a sufficiency condition for enough comparatives in the general case. Having a particular degree of height or speed may certainly enable one to reach a shelf or win a race, respectively, but neither property can, on its own, guarantee a particular outcome. In other words, while enough comparatives attribute to their subjects properties that play an important role in the potential for

11 One exception is Zhang (2018), who argues that some enough comparatives are not modal. Other analyses disagree chiefly as to the location and/or source of the modal component (see Grano 2020).

12 The necessity condition also predicts negative complement entailments from negated circumstantial enough comparatives. This is upheld in the case of static-adjective constructions (e.g., Nima was not tall enough to reach the shelf), but negated dynamic-adjective constructions present a more complicated picture. These cases cannot be discussed here, but are examined in Nadathur 2019. 
complement realization, these properties cannot bring their complements about, as is required for implicative inferences. Enough attributions are, at base, stative predications, and thus cannot represent causing actions in the implicative sense.

\subsection{Actionable properties and causal sufficiency}

How, then, does implicativity come about in enough constructions? As argued by Nadathur (2017, 2019), the actionable nature of implicative enough attributions makes a crucial addition to the underlying semantics. The importance of 'actionability' becomes clear when we consider the enabling relationship between enough attributions and the realization of their complements.

In the static example in (23), we establish the degree requirement by considering Nima's height in the circumstantially-accessible worlds where he reaches the shelf.

(23) Nima was tall enough to reach the shelf.

$\not \rightarrow$ Nima reached the shelf.

These worlds have more than a height requirement in common, however. As shelf-reaching worlds, they must, ipso facto, also be worlds in which Nima attempts to reach the shelf-i.e., in which he initiates a chain of events which results in his reaching the shelf. In the presence of the enabling height, an initiating action (e.g., raising his arm) can be both a necessary and a sufficient cause for the complement. In other words, the property attribution makes it possible for there to be an implicativestyle causally necessary and sufficient condition, but—crucially—-this is the extent of the connection between height and a causal chain. The (static) matrix property and the causing action have no intrinsic link: having the requisite height to reach the shelf does not suggest anything about the status of a causing action.

The picture is different with dynamic-adjective enough constructions like (20):

(20) Juno was fast enough to win the race.

$\rightsquigarrow$ Juno won the race.

Accessible worlds in which Juno wins the race must be worlds in which she is capable of the requisite speed, as well as worlds in which she acts to win the race. In this case, however, her potential speed and the action which directly causes the win do have an intrinsic connection: the action which brings about Juno's win is one which is characterized by, or manifests, the requisite speed. ${ }^{13}$ That is, Juno's (race-time) manifestation of the property attributed to her by (20) is understood to be a necessary and sufficient cause for the realization of the complement.

At this point, the structure of dynamic-adjective enough constructions parallels the hypothetical guarantee structure proposed for ABLE. Via the actionable nature

13 Running in a race is, generally speaking, the last action to be taken in a chain of events leading up to a win (after registering, arriving at the start, and so on). It follows that running at the requisite speed is a sufficient as well as a necessary cause, by way of being the last necessary cause to be settled. 
of the properties they attribute, dynamic-adjective enough claims background a causal connection which their static-adjective counterparts lack: they presuppose not only the necessity of some degree $d_{\mathrm{n}}$ of the matrix adjective, but moreover that a manifestation of this property is causally necessary and causally sufficient for the enough complement. Like ABLE, then, dynamic-adjective enough constructions have the first two components of implicative semantics. Unlike lexical implicatives, however, neither construction forces the realization of its causal prerequisite, instead attributing only a particular actionable property to their agents-specifically, the potential (or possibility) for the agent to realize the causing action.

For dynamic-adjective enough as well as for ABLE, this semantic distinction explains the absence of implicative entailments in English and, by extension, under imperfective marking in French. In addition, the transparent, lexically-specific nature of an enough attribution illuminates the availability of defeasible implicative inferences: a manifestation of (e.g.) speed of at least degree $d_{\mathrm{n}}$ is a reasonable pragmatic inference to draw from a related actionable-property attribution. We can be more precise about how such an inference arises - and explain how perfective marking gives rise to full implicative entailments-by taking a closer look at how actionable-property attributions fare under aspectual modification.

\subsection{Aspectual coercion and instantiation}

Property attributions of any sort are stative predicates: they describe an entity's characteristics, but not an action or event. As (29) shows, statives resist straightforward composition with the perfective aspect (Dowty 1986, a.o.).

?Nima a été grand.

'?Nima was-PFV tall.'

The problem is typically explained in terms of a mismatch between the features of the stative and the requirements of a perfective operator, which selects for eventive (dynamic) predicates. Following Moens \& Steedman (1988); de Swart (1998); Bary (2009), mismatches are reparable just in case the stative can be 'coerced' into an eventive reinterpretation with a close relationship to the original predicate.

One example of aspectual coercion comes from inchoative interpretations of perfectively-marked statives. (30) naturally describes a reference-time transition into the relevant state, rather than describing the state itself.

$$
\begin{aligned}
& \text { Soudain, Anne a été triste. } \\
& \text { 'Suddenly, Anne was-PFV sad.' }
\end{aligned}
$$

$\rightarrow$ Anne became sad suddenly.

De Swart proposes to formally capture reinterpretations by assuming that aspectual class mismatches trigger the insertion of a coercion operator between an 
eventuality predicate and grammatical aspect. Generalized coercion operators only specify the feature to be changed. The specific semantic form imposed by the coercion operator is then selected from a predetermined set of options, on the basis of contextual cues and compatibility with the underlying predicate. Thus, while soudain ('suddenly') in (30) indicates punctuality, privileging an inchoative resolution of the stative-to-eventive transition, a longer reference time might instead coerce a maximal or completive reading, as in (31). ${ }^{14}$

Hier, Anne a été triste.

$\rightsquigarrow$ Anne is no longer sad today

'Yesterday, Anne was-PFV sad.'

$\sim$ Yesterday contains a maximal (completed) eventuality of Anne being sad.

Nadathur (2019) argues that actionable-property attributions are, as a default, subject to a third, specialized operation of instantiative coercion. This is reflected in the contrasting interpretations for Alma être rapide ('Alma be fast') in (32). Since imperfective aspect is a priori compatible with statives, Alma's speed in (32a) remains latent. (32b), however, describes an event of Alma manifesting her speed.

a. Alma était rapide.

'Alma was-IMPF fast.' $\sim$ Alma could do things fast. b. Alma a été rapide.

'Alma was-PFV fast.'

$\sim$ Alma did something fast.

Instantiative coercion only applies to action- or event-oriented statives. There is, in general, no sensible notion of a height-characterized action, and it is thus impossible for the stative in (29) to receive an instantiated reading. Instantiative coercion, in essence, trades on the intuition that an actionable property attribution can only be made in view of the potential for 'witnessing' events (over the course of which the stative description also obtains). Witness relationships might be established by meaning postulates like (33), which links a stative (individual-describing) fast $t_{\mathrm{st}}$ to an eventive (action-describing) fast $t_{\mathrm{ev}}$. Roughly speaking, instantiative coercion then substitutes a contextually-salient witnessing eventive $\left(R_{\mathrm{ev}}\right)$ for the original stative $\left(S_{\mathrm{st}}\right)$ as the input to aspect. (33)-(34) are based on Nadathur 2019 (365-366). ${ }^{15}$

$$
\begin{aligned}
& \llbracket \text { fast }_{\mathrm{st}} \rrbracket=\lambda w \lambda e \lambda x . \diamond \exists e^{\prime}\left[e^{\prime} \sqsubseteq e \wedge \text { fast }_{\mathrm{ev}}\left(e^{\prime}\right)(w) \wedge \operatorname{AGENT}\left(e^{\prime}\right)=\operatorname{ThEmE}(e)=x\right] \\
& \llbracket \mathrm{INST} \rrbracket:=\lambda w \lambda S_{\mathrm{st}} \lambda R_{\mathrm{ev}} \lambda e . \exists e^{\prime}\left[e \sqsubseteq e^{\prime} \wedge R(e)(w) \wedge S\left(e^{\prime}\right)(w) \wedge \operatorname{witness}(R, S)\right]
\end{aligned}
$$

14 The maximal interpretation corresponds to de Swart's (1998) BOUND, or Bary's (2009) complexive operator. Bary provides formal proposals for inchoative and maximal coercion operators.

15 As far as I know, there is no other formal proposal for instantiative coercion; Homer's (2011) related but non-equivalent proposal is discussed in $\$ 5$. However, there are a number of informal references to an operation like (34): among others, de Swart lists a DYNAMIC operator with a similar effect, and Goldsmith \& Woisetschlaeger (1982) mention a similar reinterpretation for actionable-property attributions like be polite in the English progressive, which also selects for eventives. 
Causality and aspect in ability, actuality, and implicativity

Dynamic-adjective enough constructions are, ultimately, actionable-property attributions. As in (32b), the combination of INST and PFV provides a witness event for Juno's speed in (35). In this case, the most salient witness is the backgrounded causal prerequisite: a race-time run by Juno, at a speed of at least $d_{\mathrm{n}} \cdot{ }^{16}$

Juno a été assez rapide pour gagner la course.

'Juno was-PFV fast enough to win the race.'

a. $\llbracket(35) \rrbracket^{w^{*}, t^{*}} \equiv \llbracket \operatorname{PST}\left(\operatorname{PFV}\left(\operatorname{INST}(\right.\right.$ Juno be fast enough to win the race $) \rrbracket^{w^{*}, t^{*}}$ $=R_{\mathrm{ev}} \rightarrow$ run $\exists e\left[\tau(e) \subseteq t\left\{t \prec t^{*}\right\} \wedge\left[\exists e^{\prime}\left[e \sqsubseteq e^{\prime} \wedge \operatorname{run}(J)(e)\left(w^{*}\right) \wedge\right.\right.\right.$

$\left.\left.\left.\left(\operatorname{SPD}(J)\left(w^{*}\right) \geq d_{\mathrm{n}}\right)\left(e^{\prime}\right) \wedge \operatorname{WITNESS}\left(\operatorname{run}(J), \operatorname{SPD}(J) \geq d_{\mathrm{n}}\right)\right]\right]\right]$,

where $d_{\mathrm{n}}$ is as defined by the necessity condition in (28).

With instantiative coercion, the dynamic-adjective attribution becomes an implicative claim: PFV + INST turns a property attribution into an assertion realizing the backgrounded causing action. This provides the missing third component of implicative semantics, thereby deriving the observed implicative entailments.

That enough entailments result from instantiative aspectual coercion is supported by their absence when a different type of coercion is privileged:

Soudain, Olga a été assez forte pour soulever un frigo, mais elle ne l'a pas fait.

'Suddenly, Olga was-PFV strong enough to lift a fridge, but she did not do it.'

As before, soudain invites an inchoative reinterpretation for the underlying stative, so that (36) describes an event of Olga entering a state in which she can perform feats of (at least) fridge-lifting strength. Crucially, because inchoative coercion does not force a strength instantiation, no complement entailment is predicted.

Finally, what happens in the absence of overt aspect? I suggested that a manifestation inference is not surprising, given the close connection between actionable properties and their witness events (cf. 33). Taking this a step farther, the defeasible implicative inference observed for English dynamic-adjective enough claims results from an interpretive ambiguity: in the absence of overt aspect, (20) can either be understood as a latent property attribution or as a description of action.

(20) Juno was fast enough to win the race.

$\rightsquigarrow$ Juno won the race.

a. Stative: At reference time, Juno was capable of speeds of at least $d_{\mathrm{n}}$.

b. Eventive: At reference time, Juno manifested a speed of at least $d_{\mathrm{n}}$.

16 Marques (2012) shows that enough implicativity is subject to one more requirement, which I cannot discuss here, for reasons of space: overlap or adjacency in the temporal specification of matrix and complement clauses. This follows, given the relationship between an actionable property and an enough complement - a property manifestation can only be the last (and thus causally sufficient) step in a causal chain for the complement if it occurs immediately prior to the complement itself. 
The availability of an implicative inference follows from the eventive interpretation option, while its defeasibility is due to the availability of the stative option. ${ }^{17}$

\section{Ability, aspect, and implicativity}

We left ABLE, at the end of $\S 3$, as a hypothetical guarantee: it presupposes the causal necessity and causal sufficiency of some (underspecified) action for the realization of its complement, and asserts that the relevant action is available to (i.e., a live possibility for) its subject. This is comparable to the base structure of a dynamicadjective enough claim, with the sole difference that an enough predicate specifies something about the nature of its causal prerequisite, and ABLE does not. Driving home Bhatt's (1999) comparison of ability to manage, the relationship between dynamic-adjective enough predicates and ABLE is comparable to the relationship between lexically-specific implicatives like dare (example 16), which partially describe their causal prerequisites, and manage, which does not.

Dynamic-adjective enough claims have actuality entailments because they attribute actionable properties to their subjects. These attributions are subject to instantiative coercion under perfective marking, forcing manifestation of the prerequisite action, and actualizing the complement as a causal consequence. On the hypothetical guarantee analysis, the asserted content of ABLE is similar: it attributes to an agent the (latent) potential for realizing some causing action. Viewed this way, ABLE makes a stative, actionable-property attribution. We therefore expect perfective marking to have the same effect as it does with dynamic-adjective enough claims: a feature mismatch triggers instantiative coercion, producing a manifestation of the actionable property (i.e., of the causing action).

Perfective ABLE is, in effect, an implicative. ABLE's lexical semantics encode the first two semantic components of implicativity (a necessary/sufficient condition causally linked to the complement). Instantiative coercion, under perfective aspect, provides the missing third component: an implicative assertion. Thus, as anticipated by Bhatt, actuality entailments are just implicative entailments. However, they are implicative entailments that arise compositionally, rather than from the meaning of ABLE alone. This account, unlike Bhatt's, explains the inferential contrast between English be able and manage, or between French pouvoir and réussir under imperfective: manage/réussir always establishes the realization of its causal prerequisite, while be able/pouvoir (ABLE) does so only under aspectual coercion.

Homer (2011) provides supporting evidence for a coercion analysis by noting the potential for perfective but non-entailing ability in contexts that license alternative forms of coercion. (37), with an inchoative reading, is comparable to (36).

17 Temporal adverbials can privilege one of the interpretations. While defeasibility is never ruled out, it is pragmatically marked in strongly episodic contexts, e.g., if (20) is prefaced by this morning. 
Causality and aspect in ability, actuality, and implicativity

Olga a pu soulever un frigo, mais elle ne l'a pas fait.

'Olga could-PFV lift a fridge, but she did not do it.'

Homer also offers an aspectual coercion analysis of actuality entailments, which is distinct from the current proposal. He treats French ability modals as circumstantial possibilities, (which, as seen in $\S 2$, does not account for their pure ability readings), and argues that they are stative predicates which require reinterpretation under perfective aspect. His proposed actualistic coercion (ACT) operator, together with perfective, returns a contextually-salient event which is simultaneous with an eventuality in the denotation of the original stative, but which can be otherwise unrelated. ${ }^{18}$ Homer argues that this directly actualizes an ability modal's prejacent, as the most salient event. Under ACT, then, perfective ability modals in effect assert their prejacents. As a result, Homer does not predict the 'non-triviality' inference which (perfective) ABLE shares with manage (see §3); on my account, these inferences follow from a shared presupposition of the complement's causal dependence.

Implicative enough constructions also distinguish the two accounts. Instantiative coercion, as noted, only applies to action-oriented statives (which stand in relation to witnessing eventives, as in 33). Homer's АCT has no such restriction. Thus, as long as the context supplies a salient eventive predicate, ACT can, in principle, apply to any stative. This seems to predict the possibility of implicativity from perfective static-adjective enough: eventive complements should be as salient for АCT in these constructions as they are in the case of ability modals. This prediction is not upheld: insofar as (38) is at all acceptable, it must have a non-entailing inchoative reading.

*/?Nima a été assez grand pour atteindre l'étagère du haut.

'Nima was-PFV tall enough to reach the topmost shelf.'

Instantiative coercion, by contrast, predicts the lack of complement entailments for static-adjective enough, since INST cannot apply to static property attributions. ${ }^{19}$

\section{Conclusion}

The semantic structure proposed for ABLE is summarized in (39). On this account, actuality entailments are real instances of implicative behaviour, produced-in composition with the perfective aspect—by the same semantic components that derive the characteristic complement entailments of lexical implicatives.

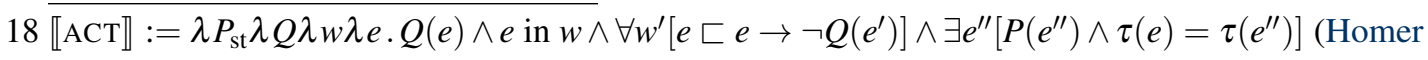
2011: 111). $Q$ is the contextually-supplied predicate; the third conjunct forces it to be bounded.

19 Additional support for the current coercion analysis may come from Alxatib (2020), who argues that Homer's ACT cannot apply in several eventive-selecting environments in Palestianian Arabic where ability roots receive actualized readings. Alxatib suggests that an operation like de Swart's DYNAMIC might do instead: I leave it for future work to determine whether or not INST is a viable candidate. 
(39) Implicative ABLE. For agent $x$, one-place predicate $A, x$ ABLE (to) $A$ :

a. presupposes the existence of an action $H$ such that $H(x)$ is causally necessary and causally sufficient for $A(x)$ in the utterance context.

b. asserts that $H(x)$ is a possibility for $x$

$\left[\nabla_{(\operatorname{circ})} H(x)\right]$

The structure of (39) not only explains the similarity between actualized ability and manage, but is further motivated insofar as it accounts for the strength of pure ability readings. An independently-observed alternation in the interpretation of statives under grammatical aspect explains the aspect-sensitivity of the ability/actuality alternation, while the parallel between (39) and dynamic-adjective enough constructions motivates construing an asserted possibility for action (in 39b) as a stative, actionable-property attribution, subject to instantiative coercion.

One puzzle introduced by (39) is that the possibility operator in an ability claimpart of the assertion (39b) — does not appear to embed the overt prejacent, as on the standard premise semantics, but instead a proposition about the backgrounded causal prerequisite. A possible way around this problem comes from Belnap (1991), who treats ability modals as standard (historical) possibilities, but possibilities which introduce selectional restrictions. Specifically, these modals select for agentive stit propositions with the surface form $A(x)$, and the underlying form $x$ stit: $[A(x)]$, which establishes that $x$ made a choice to ensure $A(x)$ (Belnap \& Perloff 1988). This analysis might be integrated with (39) by revising $x$ stit: $[A(x)]$ to the proposition that $x$ takes some action (in order) to cause $A(x) .{ }^{20}$ On this approach, ability modals can be unified with other possibilities in directly embedding their prejacents: the 'hidden' causal structure of a stit prejacent produces the crucial 'hypothetical guarantee' form.

This suggestion cannot be fully explored here, but it has the positive consequence of aligning ability with teleological modal claims: the difference between ability and a claim like Ria can take the train to go to London is that the latter makes explicit a potential action (taking the train) which will bring about a stated goal (reaching London), while ability makes only the goal explicit. Insofar as it is the structure in (39) which drives the actualization potential of ability, we predict actuality inferences wherever this structure arises: i.e., from predicates, like teleological modals, which combine stativity and telicity by linking a potential for action to assumptions about its causal consequences. This suggests — in parallel with Mari (2016) — that Hacquard's (2006) original characterization of root modals as the actualizing class should be refined to include just the teleological modalities. ${ }^{21}$ A unified analysis of abilitative and teleological modals, taking the causal revision of the stit analysis as a starting point, thus seems to be a direction well worth pursuing in future work.

20 A potential challenge to this approach comes from the existence of actualizing but non-agentive uses of ability (as in, e.g., The lift was able to carry 15 people). Such examples have a dispositional flavour, however, and may independently be amenable to a causal analysis.

21 I. Francez (p.c.) and D. Privoznov (p.c.) have also suggested a teleological characterization. 
Causality and aspect in ability, actuality, and implicativity

\section{References}

Alxatib, Sam. 2020. The ability root in Palestinian Arabic and its actuality entailment. Natural Language and Linguistic Theory (preprint). doi:10.1007/s11049020-09490-y.

Baglini, Rebekah \& Itamar Francez. 2016. The implications of managing. Journal of Semantics 33(3). 541-560. doi:10.1093/jos/ffv007.

Bary, Corien. 2009. Aspect in Ancient Greek. A semantic analysis of the aorist and imperfective: Radboud University $\mathrm{PhD}$ dissertation.

Belnap, Nuel. 1991. Backwards and forwards in the modal logic of agency. Philosophy and Phenomenological Research 51. 777-807. doi:10.2307/2108182.

Belnap, Nuel \& Michael Perloff. 1988. Seeing to it that: a canonical form for agentives. Theoria 54. 175-199. doi:10.1111/j.1755-2567.1988.tb00717.x.

Bhatt, Rajesh. 1999. Covert modality in non-finite contexts: University of Pennsylvania $\mathrm{PhD}$ dissertation. doi:10.1515/9783110197341.

Brown, Mark. 1988. On the logic of ability. Journal of Philosophical Logic 17. 1-26. doi:10.1007/BF00249673.

Castroviejo, Elena \& Isabel Oltra-Massuet. 2018. Generic and action-dependent abilities in Spanish 'be capable'. Glossa 3. 1-32. doi:10.5334/gjgl.495.

Coleman, Linda. 1975. The case of the vanishing presupposition. Berkeley Linguistics Society (BLS) 1. 78-89. doi:10.3765/bls.v1i0.2348.

Dowty, David. 1986. The effects of aspectual class on the temporal structure of discourse: semantics or pragmatics. Linguistics and Philosophy 9(1). 37-61. doi:10.1007/BF00627434.

Goldsmith, John \& Erich Woisetschlaeger. 1982. The logic of the English progressive. Linguistic Inquiry 13. 79-89. www.jstor.org/stable/4178260.

Grano, Thomas. 2020. Enough clauses, (non)finiteness, and modality. Ms., Indiana University.

Hacquard, Valentine. 2005. Aspects of too and enough constructions. Semantics and Linguistic Theory (SALT) 15. 80-97. doi:10.3765/salt.v15i0.2919.

Hacquard, Valentine. 2006. Aspects of modality: Massachusetts Institute of Technology PhD dissertation.

Hacquard, Valentine. 2020. Actuality entailments. In Daniel Gutzmann, Lisa Matthewson, Cécile Meier, Hotze Rullman \& Thomas Ede Zimmerman (eds.), The Wiley Blackwell Companion to Semantics, 1-26. Oxford: Wiley. doi:10.1002/9781118788516.sem052.

Homer, Vincent. 2011. French modals and perfective. West Coast Conference on Formal Linguistics (WCCFL) 28. 106-114.

Karttunen, Lauri. 1971. Implicative verbs. Language 47(2). 340-358. doi:10.2307/412084. 
Karttunen, Lauri \& Stanley Peters. 1979. Conventional implicature. In Choon-Kyu Oh \& David Dinneen (eds.), Syntax and semantics, vol. 11, 1-56. New York: Academic Press.

Kaufmann, Stefan. 2013. Causal premise semantics. Cognitive Science 37(6). 1136-1170. doi:10.1111/cogs.12063.

Kennedy, Chris. 2001. Polar opposition and the ontology of degrees. Linguistics and Philosophy 24(1). 33-70. doi:10.1023/A:1005668525906.

Kenny, Anthony. 1976. Human ability and dynamic modalities. In Julia Manninen \& Raimo Tuomela (eds.), Essays of explanation and understanding, 209-232. Dordrecht: Reidel.

Klein, Wolfgang. 1994. Time in language. New York: Routledge.

Kratzer, Angelika. 1998. More structural analogies between pronouns and tense. Semantics and Linguistic Theory (SALT) 8. 92-110. doi:10.3765/salt.v8i0.2808.

Louie, Meagan. 2014. Actuality entailments in Blackfoot (sleepers and imposters). Workshop on Structure and Constituency in the Languages of the Americas (WSCLA) 18.

Maier, John. 2018. Ability, modality, and genericity. Philosophical Studies 175. 411-428. doi:10.1007/s11098-017-0874-9.

Mandelkern, Matthew, Ginger Schultheis \& David Boylan. 2017. Agentive modals. The Philosophical Review 126(3). 301-343. doi:10.1215/00318108-3878483.

Mari, Alda. 2016. Actuality entailments: when the modality is in the presupposition. Logical Aspects of Computational Linguistics (LACL) 10054. 191-210. doi:10.1007/978-3-662-53826-5_12.

Mari, Alda \& Fabienne Martin. 2009. Interaction between aspect and verbal polysemy: (im-)perfectivity and (non-)implicativity. Handout from Séminaire temporalité: typologie et acquisition, Paris.

Marques, Rui. 2012. Covert modals and (non-)implicative readings of too/enough constructions. In Werner Abraham \& Elisabeth Leiss (eds.), Covert patterns of modality, 238-266. Cambridge Scholars Publishing.

Meier, Cécile. 2003. The meaning of too, enough and so ... that. Natural Language Semantics 11. 69-107. doi:10.1023/A:1023002608785.

Moens, Mark \& Mark Steedman. 1988. Temporal ontology and temporal reference. Computational Linguistics 14. 15-28. https://dl.acm.org/doi/10.5555/55056. 55058.

Nadathur, Prerna. 2016. Causal necessity and sufficiency in implicativity. Semantics and Linguistic Theory (SALT) 26. 1002-1021. doi:10.3765/salt.v26i0.3863.

Nadathur, Prerna. 2017. Implicative inferences and causality in enough and too constructions. Amsterdam Colloquium 21. 355-364.

Nadathur, Prerna. 2019. Causality, aspect, and modality in actuality inferences: Stanford University PhD dissertation. 
Causality and aspect in ability, actuality, and implicativity

Piñón, Christopher. 2009. Another look at the actuality entailment of certain modals. Handout from Genericity: Interpretation and Uses, Paris.

Portner, Paul. 2009. Modality. Oxford: Oxford University Press.

Schulz, Katrin. 2011. If you'd wiggled A, then B would've changed. Synthese 179. 239-251. doi:10.1007/s11229-010-9780-9.

von Stechow, Arnim, Svetlana Krasikova \& Doris Penka. 2004. The meaning of German um zu: necessary condition and enough/too. Handout from Workshop on Modal Verbs and Modality, Tübingen.

de Swart, Henriëtte. 1998. Aspect shift and coercion. Natural Language and Linguistic Theory 16. 347-385. doi:10.1023/A:1005916004600.

Thalberg, Irving. 1972. Enigmas of agency: Studies in the philosophy of human action. London: George B. Allen Unwin.

Zhang, Linmin. 2018. Enough, too, and causal dependence. Sinn und Bedeutung (SuB) 22. 481-498.

Prerna Nadathur

Department of Linguistics

University of California, Berkeley

1203 Dwinelle Hall

Berkeley, California

pnadathur@gmail.com 